\title{
A Multi-resistance Plasmid Isolated from Commensal Neisseria Species is Closely Related to the Enterobacterial Plasmid RSF1010
}

\author{
By RAFAEL ROTGER, † FRANCISCA RUBIO AND CÉSAR NOMBELA* \\ Departamento de Microbiologia, Facultad de Farmacia, Universidad Complutense, \\ 28040-Madrid, Spain
}

(Received 11 March 1986; revised 10 April 1986)

\begin{abstract}
pFM739, an R plasmid from Neisseria sicca that encodes penicillin, streptomycin and sulphonamide resistance, and the enterobacterial IncQ(P-4) plasmid RSF1010, which encodes streptomycin and sulphonamide resistance, were incompatible, and were mobilized by the same conjugative plasmids. Restriction mapping confirmed a high degree of similarity between both R plasmids; pFM739 carried DNA fragments corresponding to the known replication and resistance regions of RSF1010. pFM739 also carried an extra segment with the same restriction map as that described for the $\beta$-lactamase-coding region of transposon $\mathrm{Tn} 3$. It is suggested that the R plasmids isolated from commensal Neisseria sp. could have resulted from transposition of a Tn3-like genetic element to an RSF1010-like plasmid, and that they contain deletion derivatives of transposon $\mathrm{Tn} 3$.
\end{abstract}

\section{INTRODUCTION}

The recent isolation, in our laboratory, of commensal Neisseria spp. strains carrying multiresistance plasmids (Rotger et al., 1981; Pintado et al., 1985) raised questions about the origin, transfer mechanisms and possible spread of these plasmids to pathogenic bacteria colonizing the same mucosal surfaces. The problem of the introduction of $\mathrm{R}$ plasmids into the genus Neisseria is of increasing concern in view of the possibility of commensal strains becoming a reservoir of $\mathbf{R}$ plasmids (Genco et al., 1984) and the fact that $R$ plasmids seem to have reached strains of Neisseria meningitidis (Dillon et al., 1983). The plasmids we have isolated from strains of Neisseria sicca, Neisseria subflava and Neisseria mucosa had the same molecular size $(9.45 \mathrm{~kb})$ and restriction patterns, and coded for a TEM-type $\beta$-lactamase, a streptomycin phosphotransferase and a sulphonamide-resistant dihydropteroate synthetase (Pintado et al., 1985). They were also stably maintained in Escherichia coli and Pseudomonas putida (Rotger et al., 1981). These properties suggested the possibility of such $\mathbf{R}$ plasmids from Neisseria spp. being related to $\mathbf{R}$ plasmids of the IncQ(P-4) group. Such plasmids are of similar size and host range and encode the same mechanisms of streptomycin and sulphonamide resistance (Heffron et al., 1977; Barth et al., 1981). In this communication we show that a close relationship exists between pFM739, from $N$. sicca, and RSF1010, a representative IncQ(P-4) plasmid encoding streptomycin and sulphonamide resistance.

\section{METHODS}

Bacterial strains, plasmids and culture media. Strains and plasmids used in this investigation are listed in Table 1. E. coli was grown in Luria Bertani (LB) broth containing $0.5 \%(\mathrm{w} / \mathrm{v})$ yeast extract, $1 \%(\mathrm{w} / \mathrm{v})$ tryptone (Difco) and $1 \%(\mathrm{w} / \mathrm{v}) \mathrm{NaCl}$, or in the same medium solidified with $2 \%(\mathrm{w} / \mathrm{v})$ agar (Difco). This medium was also used for selection in all genetic transfer experiments, except when sulphamethoxazole was the selective agent. In this case Mueller-Hinton agar (BBL) supplemented with $5 \%(\mathrm{v} / \mathrm{v})$ lysed horse blood was used. Incubations were always done at $37^{\circ} \mathrm{C}$.

\footnotetext{
† Present address: Departamento de Microbiología, Facultad de Ciencias, Universidad de Palma de Mallorca, Spain.
} 
Table 1. Bacterial strains and plasmids used

Strain

E. coli K12 HB101

E. coli K12 NEM259

E. coli K12 185

Plasmid

pFM739

pFM202

RSF1010

R124

pIP113

RP4

Rts 1
Relevant characteristics*

$$
\begin{aligned}
& \text { ara-14 galK2 hsdS20 lacY1 leu } \\
& \text { mtl-1 proA2 recA13 rpsL20 } \\
& \text { supE44 thi xyl-5 } \\
& \text { hsd } R_{k} \text { hsdM } M_{k}^{+} \text {met supE supF } \\
& \mathrm{Nal}^{\mathrm{R}}
\end{aligned}
$$

$\mathrm{Ap}^{\mathrm{R}} \mathrm{Sm}^{\mathrm{R}} \mathrm{Su}^{\mathrm{R}}$

$\mathrm{Ap}^{\mathrm{R}}$

$\mathrm{Sm}^{R} \mathrm{Su}^{\mathrm{R}}$ IncQ(P-4)

$\mathrm{Tra}^{+} \mathrm{Tc}^{\mathrm{R}}$ IncFIV

$\mathrm{Tra}^{+} \mathrm{Tc}^{\mathrm{R}}$ IncN

$\mathrm{Tra}^{+} \mathrm{Ap}^{\mathrm{R}} \mathrm{Km}^{\mathrm{R}} \mathrm{Nm}^{\mathrm{R}} \mathrm{Tc}^{\mathrm{R}}$

IncP(P-1)

$\mathrm{Tra}^{+} \mathrm{Km}^{\mathrm{R}}$ IncT
Origin†

V. Rubio

M. Vicente

J. M. Ortiz

This laboratory; Pintado et al. (1985)

This laboratory; Rotger \& Nombela (1983)

J. Jofre

J. Jofre

J. Jofre

J. Jofre

J. Jofre

* Ap, ampicillin; Sm, streptomycin; Su, sulphonamides; Tc, tetracycline; $\mathrm{Km}$, kanamycin; Nm, neomycin.

† Addresses: V. Rubio, Antibiotics S.A., Madrid, Spain; M. Vicente, Instituto de Biología Celular, Madrid, Spain; J. M. Ortiz, Facultad de Medicina, Santander, Spain; J. Jofre, Facultad de Biología, Barcelona, Spain.

Genetic transfer. $E$. coli cells were transformed with isopropanol-precipitated plasmid DNA, as described by Cohen et al. (1972). Mating experiments were done by mixing exponential phase cultures of donor and recipient strains $(1: 1)$, and incubating for $90 \mathrm{~min}$. Alternatively, the mating mixture was retained on nitrocellulose filters as described previously (Rotger et al., 1981). The antibiotics used for selection and their concentrations were: carbenicillin, $500 \mu \mathrm{g} \mathrm{ml}^{-1}$; kanamycin, $50 \mu \mathrm{g} \mathrm{ml}^{-1}$; nalidixic acid, $50 \mu \mathrm{g} \mathrm{ml}^{-1}$; streptomycin, $25 \mu \mathrm{g} \mathrm{ml}^{-1}$ or $300 \mu \mathrm{g} \mathrm{ml}^{-1}$ for selection of plasmid or chromosomal resistance markers respectively; sulphamethoxazole, $1 \mathrm{mg} \mathrm{m}^{-1}$; and tetracycline, $10 \mu \mathrm{g} \mathrm{m}^{-1}$. The results obtained were consistently reproduced after several determinations.

Preparations and characterization of plasmid DNA. The rapid method of Holmes \& Quigley (1981) was used for plasmid detection. For restriction endonuclease analysis, plasmid DNA was purified by centrifugation of cleared lysates, and prepared according to Grinsted et al. (1978), in caesium chloride ethidium bromide equilibrium density gradients. Covalently closed circular DNA preparations were exhaustively dialysed and ethanolprecipitated. Restriction endonucleases were purchased from BRL and used according to the manufacturer's instructions. Electrophoresis was done in polyacrylamide $(4 \%, \mathrm{w} / \mathrm{v})$ or agarose $(0.7$ to $1 \%)$ gels, essentially as described by Meyers et al. (1976). $\lambda$ phage DNA, digested with HindIII and EcoRI, was used as a molecular size marker (Southern, 1979). Analyses with each endonuclease or pair of endonucleases were done at least twice, with reproducible results.

Plasmid incompatibility tests. To study incompatibility between plasmids pFM739 and RSF1010, the former was transformed into $E$. coli K12 HB101(RSF1010) by selecting for carbenicillin resistance. Several of the corresponding transformant clones were analysed by agarose gel electrophoresis in order to examine the resulting plasmid complement. The experiment was repeated three times with the same results.

\section{RESULTS}

\section{Incompatibility of plasmids pFM739 and RSF 1010}

Plasmid pFM739, from $N$. sicca 739, has been described as an extrachromosomal element encoding a triple resistance phenotype. In order to examine compatibility relationships between pFM739 and the enterobacterial plasmid RSF1010, the former was transformed into E. coli K12 HB101(RSF1010), and the cells were plated on to medium containing carbenicillin. Of 12 transformant clones analysed, 11 carried only one plasmid, which was the same size as pFM739, whereas the remaining clone carried both plasmids (data not shown). This clone was subcultured overnight and plated on to non-selective medium. Another 12 clones were examined and all of them carried only one plasmid, which was the same size as pFM739. Similar experiments were done with pFM202, a 7 kb gonococcal plasmid (Rotger \& Nombela, 1983); however, pFM202 
Table 2. Mobilization of plasmids pFM739 and RSF1010 by pIP113 and RP4

After mating, cells were plated on media containing: nalidixic acid, to determine the number of recipients; nalidixic acid with tetracycline (conjugative plasmid marker), to determine the number of transconjugants; or streptomycin (mobilized plasmid marker), to measure mobilization of the nonconjugative plasmid.

$\begin{array}{lcc}\begin{array}{c}\text { Conjugative } \\ \text { plasmid }\end{array} & \begin{array}{c}\text { Conjugation } \\ \text { per recipient }\end{array} & \begin{array}{c}\text { Mobilized } \\ \text { plasmid }\end{array} \\ \text { pIP113 } & 0.4 & \text { RSF1010 } \\ \text { pIP113 } & 0.3 & \text { pFM739 } \\ \text { RP4 } & 0.4 & \text { RSF1010 } \\ \text { RP4 } & 0.8 & \text { pFM739 }\end{array}$

$\overbrace{\text { Per transconjugant }}^{\text {Mobilization frequency }}$
$\begin{array}{cc}1.0 \times 10^{-6} & \text { Per recipient } \\ 4.1 \times 10^{-6} & 4.2 \times 10^{-7} \\ 1.0 & 1.1 \times 10^{-6} \\ 0.9 & 0.4 \\ & 0.7\end{array}$

and RSF1010 stably coexisted in the same cells. These results clearly showed that pFM739 displaced RSF1010 upon appropriate selection. We concluded that pFM739, a plasmid isolated from a commensal strain of $N$. sicca, belongs in the IncQ(P-4) incompatibility group, which has been classically regarded as a group of Pseudomonas and enterobacterial plasmids (Guerry et al., 1974).

\section{Genetic mobilization}

$N$. sicca 739 can transfer pFM739 to $E$. coli in an apparently conjugal process, although no plasmid DNA large enough to encode sex factor activity has been detected in the donor strain (Pintado et al., 1985). In order to compare plasmid pFM739 and RSF1010 further with regard to their mobilization by conjugative plasmids between $E$. coli strains, we transferred plasmids R124 (IncFIV), pIP113 (IncN), RP4 (IncP) and Rts1 (IncT) to E. coli K12 HB101 carrying either pFM739 or RSF1010. Plasmids were transferred by conjugation, and transconjugants were selected and shown to maintain both plasmids stably. Mobilization of pFM739 and RSF 1010 was studied by mating with $E$. coli $\mathrm{K} 12185$ (nalidixic acid resistant) and by selecting for either the mobilized or the conjugative plasmid independently. It is known that RSF1010 can be efficiently mobilized by IncP plasmid but very poorly or not at all by others (Barth et al., 1981). Our results confirmed this, since RSF1010 was mobilized at a high frequency by RP4 (IncP) and much less efficiently by pIP113 (IncN). Other conjugative plasmids gave no detectable mobilization (Table 2). The behaviour of pFM739 was again identical to that of RSF1010 in this respect (Table 2), suggesting a high degree of similarity.

\section{Restriction endonuclease analysis}

The comparison between the $N$. sicca plasmid pFM739 and the enterobacterial plasmid RSF 1010 was extended by analysis with several restriction endonucleases. This analysis enabled us to estimate a size of $9.45 \mathrm{~kb}$ for pFM739, by addition of the sizes of its fragments. This value is more accurate than the approximate value of $6.0 \mathrm{MDa}$ that was estimated by agarose gel electrophoresis of the plasmid (Pintado et al., 1985). Both plasmids had unique restriction sites for EcoRI (data not shown) and pFM739 had an additional unique site for BamHI.

Several bands were common to both plasmids after digestion with restriction endonucleases and electrophoresis of the fragments: four after digestion with HinfI, three with AvaI, two with HincII and one with PstI (Fig. 1). Partial and double digestions were also done and all these data enabled us to prepare a restriction map of pFM739 (Fig. 2); this was compared with the published restriction map of RSF1010 (Bagdasarian et al., 1981). The restriction patterns of sulphonamide and streptomycin resistance determinants as well as the replication region of RSF1010 appeared to be shared by pFM739. Notable differences were observed between the $2.44 \mathrm{~kb}$ AvaI fragment of pFM739 and the corresponding fragment of RSF1010; the former was 


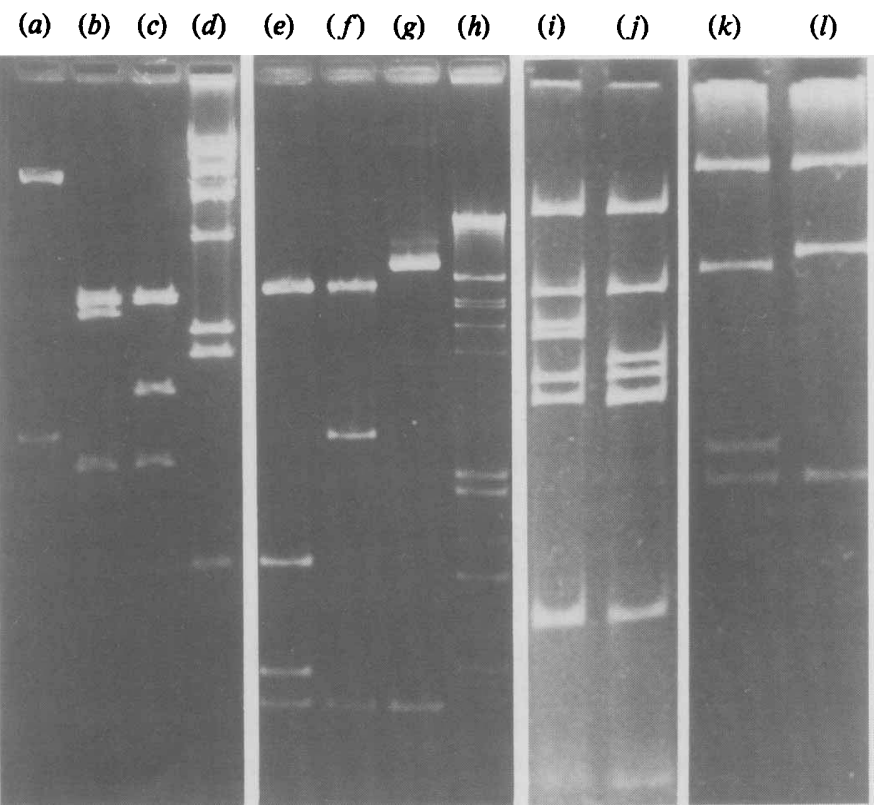

Fig. 1. Agarose (lanes $a$ to $h$ ) or polyacrylamide (lanes $i$ to $l$ ) gel electrophoresis of fragments produced by treatment of plasmids pFM739 and RSF1010 with various restriction endonucleases. (a) pFM739 treated with EcoRI plus BamHI; (b) pFM739 treated with AvaI; (c) RSF1010 treated with AvaI; (d) $\lambda$ phage DNA treated HindIII (sizes of fragments in kb are 23.7, 9.46, 6.61, 4.26, 2.26, 1.98); (e) pFM739 treated with PstI plus BamHI; $(f)$ pFM739 treated with PstI; $(g)$ RSF1010 treated with PstI; $(h) \lambda$ phage DNA treated with EcoRI plus HindIII [sizes of fragments in kb are 21.8, 5.24 and 5.05 (appearing in one band in this gel), 4.21, 3.41, 1.98, 1.9, 1.57, 1.32, 0.83, 0.84]; $(i)$ pFM739 treated with HinfI; $(j)$ RSF1010 treated with HinfI; $(k)$ pFM739 treated with HincII; $(l)$ RSF1010 treated with HincII.

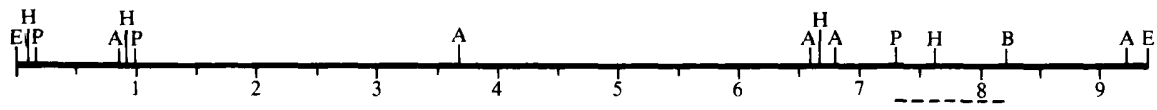

$\mathrm{pSF} 1010$

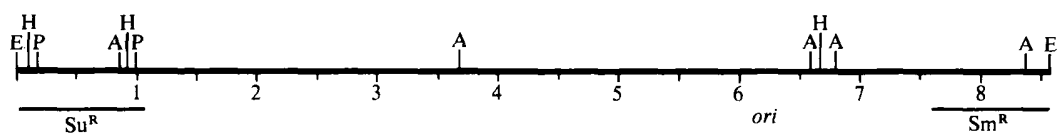

Fig. 2. Restriction maps of plasmids pFM739 and RSF1010. The location of resistance genes and the replication origin in RSF1010 has been described by Badgasarian et al. (1981), Barth et al. (1981) and Sakaguchi (1982). The dotted line below pFM739 indicates the region which does not appear in RSF 1010. The $0 \cdot 2 \mathrm{~kb}$ AvaI fragment of RSF1010 and pFM 739 was not detected in our electrophoretic system, but could be deduced from the difference with other endonuclease restriction treatments and from the previously published analysis of RSF1010. A, AvaI; B, BamHI; E, EcoRI; H, HincII; P, PstI.

$0.85 \mathrm{~kb}$ longer, and carried the single BamHI site of pFM749 as well as PstI and HincII restriction sites, all of which are absent in RSF1010. The restriction map of this extra region is very similar to that of the $\beta$-lactamase-encoding region of Tn3 (Heffron et al., 1981). This observation is in agreement with the ability of pFM739 to code for a TEM-type $\beta$-lactamase (Rotger et al., 1981; Cenamor et al., 1986).

\section{DISCUSSION}

The discovery of multi-resistance plasmids in commensal Neisseria spp. (Pintado et al., 1985) represents a clear demonstration that these bacteria can harbour and maintain resistance plasmids that have arisen in nature. The results presented above clearly show that a high degree 
of similarity exists between pFM739, a plasmid isolated from $N$. sicca, and RSF1010, a typical IncQ(P-4) R plasmid that was originally isolated from enteric bacteria (Guerry et al., 1974), and that codes for streptomycin and sulphonamide resistance. Both plasmids were incompatible and were mobilized by the same conjugative plasmids. Their restriction maps showed that pFM739 could have resulted from the transposition of a fragment of a Tn3-like genetic element to a plasmid of the RSF1010 type. Consistent with this interpretation, pFM739 DNA, labelled with $\left[\alpha-{ }^{32}\right.$ P]GTP by nick-translation, hybridized with the DNA fragments obtained by AvaI digestion of RSF1010 (data not shown). In fact, the transposition of Tn3-like genetic elements to RSF1010-related plasmids, which acquire the capacity to code for a TEM-type $\beta$-lactamase in this way, has been shown to occur in nature as well as in the laboratory (Heffron et al., 1977; Yamada et al., 1979). Plasmids that arose in this way, were very similar to pFM739, but carried the whole transposon. On the other hand, gonococcal $\beta$-lactamase plasmids have been shown to carry a $\operatorname{Tn} 3$ fragment, with a restriction map very similar to that of the $\operatorname{Tn} 3$ fragment that seems to be part of pFM739, and these are considered to be deletion derivatives of plasmid bearing the entire Tn 3 transposon. The possession of this incomplete and therefore non-transposable Tn3like segment seems to be the only similarity between pFM739 and the gonococcal penicillinase plasmids, which so far do not encode any other resistances and which have restriction patterns and incompatibility groups very different from those of the plasmid described here (Fayat et al., 1982).

The spread of IncQ plasmids to other, possibly pathogenic bacterial species was first reported by Albritton et al. (1982), who identified sulphonamide-resistance plasmids in Haemophilus ducreyi. The presence of pFM739-like plasmids in several strains of commensal Neisseria spp. points to the possibility of further spread of such nonconjugative multiple resistance plasmids to other pathogenic or opportunistic bacteria.

This investigation was supported by grant $83 / 726$ from Fondo de Investigaciones Sanitarias de la Seguridad Social.

\section{RE F ER ENCES}

Albritton, W. L., Brunton, J. L., Slaney, L. \& MCLean, I. (1982). Plasmid-mediated sulfonamide resistance in Haemophilus ducreyi. Antimicrobial Agents and Chemotherapy 21, 159-165.

Bagdasarian, M., Lurz, R., Ruckert, B., Franklin, F. C. H., Bagdasarian, M. M., Frey, J. \& Timmis, K. N. (1981). Specific-purpose plasmid cloning vectors. II. Broad host range, high copy number, RSF1010-derived vectors, and a host vector system for gene cloning in Pseudomonas. Gene 16, 237-247.

BARTH, P. T., TOBIN, L. \& Sharpe, G. S. (1981). Development of broad host-range plasmid vectors. In Molecular Biology, Pathogenicity and Ecology of Bacterial Plasmids, pp. 439-448. Edited by S. B. Levy, R. C. Clowes \& E. L. Koenig. New York: Plenum Press.

Cenamor, R., Rotger, R. \& Nombela, C. (1986). Characterization of $\beta$-lactamases produced by commensal Neisseria sicca and Branhamella catarrhalis. Microbiología 2, 29-36.

Cohen, S. N., Chang, A. C. Y. \& Hsu, L. (1972). Nonchromosomal antibiotic resistance in bacteria: genetic transformation of Escherichia coli by R-factor DNA. Proceedings of the National Academy of Sciences of the United States of America 69, 21102114.

Dillon, J. R., Pauze, M. \& Yeung, K.-H. (1983). Spread of penicillinase-producing and transfer plasmids from the gonococcus to Neisseria meningitidis. Lancet 1, 779-781.
Fayet, O., Froment, Y. \& Piffaretti, J. C. (1982). $\beta$ Lactamase-specifying plasmids isolated from Neisseria gonorrhoeae have retained an intact right part of a Tn3-like transposon. Journal of Bacteriology 149, 136-144.

Genco, C. A., Knapp, J. S. \& Clark, V. L. (1984). Conjugation of plasmids of Neisseria gonorrhoeae to other Neisseria species: potential reservoirs for the $\beta$ lactamase plasmid. Journal of Infectious Diseases 150, $397-401$.

Grinsted, J., Bennett, P. M., Higginson, S. \& Richmond, M. H. (1978). Regional preference of insertion of Tn501 and Tn802 into RP1 and its derivatives. Molecular and General Genetics 166, 313320.

Guerry, P., Van Embden, J. D. A. \& Falkow, S. (1974). Molecular nature of two non-conjugative plasmids carrying drug resistance genes. Journal of Bacteriology 117, 619-630.

HefrRon, F., Rubens, C. \& Falkow, S. (1977). Transportation of a plasmid DNA sequence that mediates ampicillin resistance: identity of laboratory-constructed plasmids and clinical isolates. Journal of Bacteriology 129, 530-533.

Heffron, F., Kostriken, R., Morita, G. \& Parker, R. (1981). Tn3 encodes a site-specific recombination system: identification of essential sequences, genes, and the actual site of recombination. Cold Spring Harbor Symposia on Quantitative Biology 45, 258268. 
Holmes, D. S. \& Quigley, M. (1981). A rapid boiling method for the preparation of bacterial plasmids. Analytical Biochemistry 114, 193-197.

Meyers, J. A., Sanchez, O., Elwell, L. P. \& FALKow, S. (1976). Simple agarose gel electrophoresis method for the identification and characterization of plasmid DNA. Journal of Bacteriology 127, 1529-1537.

Pintado, C., Salvador, C., Rotger, R. \& Nombela, C. (1985). Multiresistance plasmids from commensal Neisseria strains. Antimicrobial Agents and Chemotherapy 27, 120-124.

Rotger, R. \& NombelA, C. (1983). Characterization of penicillin-resistant $\beta$-lactamase-producing strains of Neisseria gonorrhoeae isolated in Spain (1977-81). Microbiología Española 36, 115-122.
Rotger, R., Pintado, C. \& Nombela, C. (1981). Multiple transmissible antibiotic resistance in commensal Neisseria. FEMS Microbiology Letters 10, 161-164.

SAKAGUCHI, K. (1982). Vectors for gene cloning in Pseudomonas and their application. In Current Topics in Microbiology and Immunology, vol. 96, Gene Cloning in Organisms other than E. coli, pp. 31-45. Edited by P. H. Hofschneider \& W. Goebel. Berlin: Springer Verlag.

SOUTHERN, E. (1979). Gel electrophoresis of restriction fragments. Methods in Enzymology 68, 152-176.

Yamada, Y., Calame, K. L., Grindley, J. N. \& NAKADA, D. (1979). Location of an ampicillin resistance transposon, $\mathrm{Tn} 1701$, in a group of small, nontransferring plasmids. Journal of Bacteriology 137, 990-999. 